This is the peer reviewed version of the following article: Sugai, L. S. M., Llusia, D., Siqueira, T., and Silva, T. S. F.. 2021. Revisiting the drivers of acoustic similarities in tropical anuran assemblages. Ecology 102(7):e03380, which has been published in final form at https://doi.org/10.1002/ecy.3380 This article may be used for non-commercial purposes in accordance with Wiley Terms and Conditions for self-archiving.

DR. LARISSA S.M. SUGAI (Orcid ID : 0000-0002-6248-291X)

DR. TADEU SIQUEIRA (Orcid ID : 0000-0001-5069-2904)

Article type : Article

Journal: Ecology

Manuscript type: Articles

Running head: Drivers of the acoustic space

\title{
Revisiting the drivers of acoustic similarities in tropical anuran assemblages
}

Larissa S. M. Sugai*1,2, Diego Llusia ${ }^{2,3,4}$, Tadeu Siqueira ${ }^{1}$, Thiago S. F. Silva ${ }^{1,5}$

${ }^{1}$ Universidade Estadual Paulista (Unesp), Instituto de Biociências, Rio Claro, 13506-900, São Paulo, Brazil.

2 Terrestrial Ecology Group (TEG), Departamento de Ecología, Universidad Autónoma de Madrid, C/ Darwin, 2, 28049, Ciudad Universitaria de Cantoblanco, Facultad de Ciencias, Edificio de Biología, C-211, Madrid, Spain.

3 Laboratório de Herpetologia e Comportamento Animal, Departamento de Ecologia, Instituto de Ciências Biológicas, Universidade Federal de Goiás, Campus Samambaia, CEP 74001-970, Goiânia, Goiás, Brazil.

This article has been accepted for publication and undergone full peer review but has not been through the copyediting, typesetting, pagination and proofreading process, which may lead to differences between this version and the Version of Record. Please cite this article as doi: $10.1002 /$ ecy.3380

This article is protected by copyright. All rights reserved 
${ }^{4}$ Centro de Investigación en Biodiversidad y Cambio Global, Universidad Autónoma de Madrid, C/ Darwin 2, E-28049, Ciudad Universitaria de Cantoblanco, Madrid, Spain.

${ }^{5}$ Biological and Environmental Sciences, Faculty of Natural Sciences, University of Stirling, Stirling, UK.

*Corresponding author. E-mail: lariagus@gmail.com

Manuscript received 23 November 2020; revised 12 February 2021; accepted 16 March 2021; final version received 29 April 2021.

This article is protected by copyright. All rights reserved 


\begin{abstract}
Acoustic signaling is key in mediating mate-choice, which directly impacts individual fitness. Because background noise and habitat structure can impair signal transmission, the acoustic space of mixed-species assemblages has long been hypothesized to reflect selective pressures against signal interference and degradation. However, other potential drivers that received far less attention can drive similar outputs on the acoustic space. Phylogenetic niche conservatism and allometric constraints may also modulate species acoustic features, and the acoustic space of communities could be a side-effect of ecological assembly processes involving other traits (e.g. environmental filtering). Additionally, the acoustic space can also reflect the sorting of species relying on public information through extended communication networks. Using an integrative approach, we revisit the potential drivers of the acoustic space by addressing the distribution of acoustic traits, body size, and phylogenetic relatedness in tropical anuran assemblages across gradients of environmental heterogeneity in the Pantanal wetlands. We found the overall acoustic space to be aggregated compared with null expectations, even when accounting for confounding effects of body size. Across assemblages, acoustic and phylogenetic differences were positively related, while acoustic and body size similarities were negatively related, although to a minor extent. We suggest that acoustic partitioning, acoustic adaptation, and allometric constraints play a minor role in shaping the acoustic output of tropical anuran assemblages and that phylogenetic niche conservatism and public information use would influence between-assemblage variation. Our findings highlight an overlooked multivariate nature of the acoustic dimension and underscore the importance of including the ecological context of communities to understand drivers of the acoustic space.
\end{abstract}

Keywords: communication, sensory ecology, sensory drive, community phylogenetics, bioacoustics.

This article is protected by copyright. All rights reserved 


\section{Introduction}

Animals use information available in the environment to make decisions that directly influence individual fitness (Danchin et al. 2004). In a variety of taxa, acoustic communication mediates mate choice and territoriality (Bradbury and Vehrencamp 2011), often favoring the intriguing cacophonous phenomena of mixed-species aggregations (Hödl 1977, Brumm 2013). Because conditions during signal transmission may impair communication, temporal and spectral components of vocalizations (acoustic traits) are traditionally considered to be under selection for optimized intraspecific communication and reduced interspecific competition (sensory-drive framework; Endler 1992). Within this framework, two main hypotheses have been largely evoked to explain present-day distributions of acoustic traits in communities: i) selection against masking interference or mismatches in mate recognition drives signal divergence (acoustic partitioning hypothesis, APH; Hödl 1977, Drewry and Rand 1983), and ii) selection for optimized transmission through the environment drives signal convergence (acoustic adaptation hypothesis, AAH; Morton 1975, Ey and Fischer 2009). Under these hypotheses, selection would favor predictable distributions of acoustic traits in communities ("acoustic space" hereafter), so that the acoustic space would be more different (dispersed) or similar (aggregated) than expected at random, respectively. However, previous conflicting results have prevented reaching general insights on these hypotheses (Kime et al. 2000, Chek et al. 2003, Boncoraglio and Saino 2007, Toledo et al. 2015, Tobias et al. 2014). Moreover, although a lot of effort has been put into understanding the acoustic space of ecological communities in the light of the sensory-drive framework (Chek et al. 2003, Boncoraglio and Saino 2007, Luther 2009, Schmidt et al. 2012, Roca and Proulx 2016), the role of ubiquitous behavioral and ecological interactions have received far less attention.

Species sorting through environmental filtering is one of the major mechanisms involved in the assembly of communities (Vellend 2016). If environmental heterogeneity determines the sorting of species with specific ecological traits, the acoustic space might emerge as a by-product of the combined effect of environmental filtering and phylogenetic niche conservatism. First, because closely related species usually share similar characteristics, including acoustic properties of their vocalizations (Kraft et al. 2007, Gingras et al. 2013, Garey et al. 2018), similar distributional patterns of phylogenetic relatedness and acoustic traits in communities could arise due to phylogenetic niche

This article is protected by copyright. All rights reserved 
conservatism (niche conservatism hypothesis, $\mathrm{NCH}$ ). Second, variation in particular acoustic features is strongly influenced by the organisms' body size (Rodríguez et al. 2014, Tonini et al. 2020), which is a key physiological and life-history trait often involved in community assembly (Kingsolver and Pfenning 2007, Farjalla et al. 2012). Variability in body size of coexisting species could thus influence how the acoustic space is distributed across communities (allometric constraint hypothesis, $\mathrm{ACH}$ ). Finally, the sorting of species mediated by body size or other ecological traits could indirectly shape the distribution of acoustic traits in communities. For instance, communities composed of species with similar body sizes would have more similar acoustic features when compared to a random distribution.

Recent theory also argues that public information use has a fundamental role in population and community dynamics, which would imply a correlation between information (e.g. through acoustic signaling) and the spatial distribution of information sources (e.g. emitters; Gil et al. 2018, Goodale et al. 2020). In this sense, acoustic signaling not only mediates conspecific communication but also functions as a venue for information transfer between species. Once social information becomes publicly available to other individuals, it would underly decisions on foraging strategies, habitat selection, competitive, and trophic interactions (Seppänen et al. 2007; Schmidt, Dall \& Van Gils 2010; Parejo \& Avilés 2016). In this sense, social information use would drive the sorting of ecologically similar species, often sharing similar acoustic traits (Goodale et al. 2010; Tobias et al. 2014), which would translate into aggregated distributions of acoustic traits (public information hypothesis, PIH).

Most approaches so far have evaluated distributional patterns of acoustic traits from local communities only, irrespective of between-communities variation and its potential ecological correlates. Because distinct drivers might produce similar patterns on the acoustic space, this approach is of limited value and has led to mixed support for the proposed hypotheses in the literature (Kime et al. 2000, Chek et al. 2003, Boncoraglio and Saino 2007, Toledo et al. 2015). A broader view about the drivers shaping the acoustic space of animal communities needs to go further and address the interrelationships between acoustic, phylogenetic, and ecological characteristics of communities.

This article is protected by copyright. All rights reserved 
Most anurans rely on acoustic communication for breeding and resource defense (Wells and Schwartz 2007) and form mixed-species choruses with abundant individuals, generating high levels of background noise, especially on the tropics (Gerhardt and Huber 2002, Berg et al. 2006). Importantly, anuran assemblages are largely structured by habitat conditions given their high dependence on water for reproduction and moisture for preventing dehydration (Wells 2007). Altogether, these characteristics provide an ideal model to test for the hypotheses determining the acoustic space of communities.

Here we investigate the potential of specific drivers to explain the acoustic space of anuran assemblages in a tropical wetland. Distinct hypotheses predict specific patterns of similarity of acoustic traits between species at the assemblage level, whereby the acoustic space would tend toward dispersion (acoustic partitioning hypothesis) or aggregation (acoustic adaptation and public information hypotheses). Nonetheless, phylogenetic niche conservatism, allometric constraints on acoustic traits, and the fact that assemblages are shaped by distinct ecological processes can indirectly influence the acoustic output of assemblages. In this sense, we use an integrative approach addressing the acoustic, phylogenetic, and ecological characteristics of assemblages while considering betweensite environmental complexity. Our approach is twofold and complementary, where we first assess the concordance on the distributions of acoustic traits, body size, and phylogenetic relatedness in local assemblages (Fig. 1a-c) and then address between-assemblage variation (Fig. 1d). We represent the distributional patterns of acoustic traits, body size, and phylogenetic relatedness in each assemblage with the average spacing between co-signaling species (mean pairwise distance; Fig. 1b) and test for non-random patterns toward aggregation or dispersion according to null distributions (Fig. 1c). To address the implications of phylogenetic niche conservatism and allometric constraints, we also test for the presence of phylogenetic signal in acoustic traits and body size and model the effect of body size on acoustic traits. Next, with causal direct and indirect relationships between the context of environmental heterogeneity (both local and landscape) and the distributions of acoustic traits, body size, and phylogenetic relatedness of assemblages, we analyze (i) the potential influence of environmental heterogeneity in selecting for species according to their ecological attributes (here represented as phylogenetic relatedness and body size), which in turn, could influence the observed acoustic space (Fig. 1d.i). We also expect: (ii) upon a positive relationship of acoustic and ecological

This article is protected by copyright. All rights reserved 
similarities across assemblages, the overall acoustic space of local assemblages would presumably be aggregated according to the public information hypothesis (Fig. 1d.ii), or dispersed, according to the acoustic partitioning hypothesis (Fig. 1d.ii); (iii) a strong relationship between acoustic and phylogenetic similarities would arise with phylogenetic niche conservatism (Fig. 1d.iii), while (iv) a strong relationship between acoustic and body size similarities would arise due to allometric constraint (Fig. 1d.iv), and (v) a relationship of acoustic similarity with increasing environmental heterogeneity would emerge according to the acoustic adaptation hypothesis (Fig. 1d.v).

\section{Methods}

\section{Sampling site selection and characterization}

We sampled anuran assemblages in an area of approximately $100 \mathrm{~km}^{2}$ located in the Nhecolândia region (Fig. 2a) of South Pantanal wetlands in Brazil (Silva and Abdon 1998). This semiarid region has a wet season from October to April and a dry season from May to September. Landscapes are characterized by permanent and seasonal ponds of fresh and brackish water embedded in a natural mosaic of grassland savannas, woody savannas, and forested areas (Evans and Costa 2013).

To capture a gradient of vegetation heterogeneity, we selected 39 permanent ponds located in landscapes ranging from forested to grassland savanna, spaced at a minimum of $1 \mathrm{~km}$ from each other (Appendix S1: Section S1, Fig. S1). We used the Normalized Difference Vegetation Index (NDVI; Rouse et al. 1974), a consolidated proxy of environmental structure (Pettorelli et al. 2011) to represent vegetation heterogeneity. NDVI was calculated from high-resolution images (RapidEye 3A, 5 m pixel size; Appendix S1: Section S1, Fig. S1) and averaged within a 200-meter radius buffer (i.e., landscape) around each sample site.

We also characterized the terrestrial and aquatic habitats in more detail, since environmental differences at distinct scales can affect the propagation of acoustic signals (Bosch and De la Riva 2004, Erdtmann and Lima 2013), in addition to influence the structuring of anuran assemblages (Silva

et al. 2011, Sugai et al. 2019b). Aquatic habitat was represented by the two first axes (summarizing $59 \%$ of the information; Appendix S1: Fig. S2) of a principal component analysis (PCA) on six variables: free water surface, aquatic vegetation, grass $<20 \mathrm{~cm}$, grass $>20 \mathrm{~cm}$, shrub vegetation and

This article is protected by copyright. All rights reserved 
pond depth (Appendix S1: Section S1). Terrestrial habitat was represented by the Leaf Area Index (LAI), a proxy of canopy openness (Bréda 2003) estimated with measurements from wide-angle optical sensors and a model of radiative transfer.

\section{Acoustic monitoring}

To determine species composition, we monitored the calling activity of anurans over the 39 sites using passive acoustic monitoring (Sugai et al. 2019a). During 10 consecutive days in the peak of the rainy season (January/17), each site was recorded for up to five consecutive days using a rotation of 22 automated acoustic recorders (Wildlife Acoustics ${ }^{\circledR}$ ) among sites. We deployed the automated recorders at 1.5 meters height on trees or wood stakes distant up to 10 meters from the ponds. Audios were set to record in stereo mode with $6 \mathrm{~dB}$ and $12 \mathrm{~dB}$ gain on each channel, at a $44.1 \mathrm{kHz}$ sample rate and 16-bit WAV format. We set a recording schedule to register two minutes every 20 minutes, starting one hour before sunset and ending one hour after sunrise (approximately from 16:30 to 07:30, UTC-4).

Each recording was examined by the main author to detect and identify advertisement calls of anuran species using aural recognition and visual inspection of spectrogram (Fast Fourier Transform $[\mathrm{FFT}]=512$, Hamming window) using the software Audacity (Audacity Team 2018) and Raven (Bioacoustics Research Program 2014). Recordings preceding sunrise and sunset were characterized by low anuran activity and high overlap with bird and invertebrate activity (cicadas and katydids). Therefore, for subsequent analyses, we used only recordings from 19:00h to 04:00h. Signaling assemblages were represented by the sum of species incidence on each hour.

\section{Acoustic traits}

Call structure is often species-specific, with temporal and spectral call parameters underlying conspecific recognition (Schwartz and Bee 2013). To characterize advertisement calls, we obtained high-quality audio recordings using "shotgun" directional microphones (Sennheiser ME66) and manual digital sound recorders (Tascam DR-40 and ZOOM H4n Pro). During the breeding season (03-07 Oct/16, 10-16 Dec/16, 22-29 Jan/17, 20-26 Feb/17), we searched for calling males from sunset to approximately 02:00 am at the sampling sites and recorded a minimum of 2 minutes from each

This article is protected by copyright. All rights reserved 
individual at a distance of about 1.5 meters. Recordings were registered at a $44.1 \mathrm{kHz}$ sampling rate, WAV format, 16-bit, using manual controls for gain levels to avoid clipping. When possible, we captured the same recorded individuals and measured their snout-to-vent length (a proxy of body size) with a digital caliper. As we were unable to obtain directional recordings of all species registered in our study area, we complemented our acoustic dataset with recordings from acoustic libraries and personal researcher's databases, totalizing 115 individuals (Appendix S1: Section S1, Table S1).

From each advertisement call, we extracted six acoustic parameters over the temporal and frequency domains: call rate (number of calls per second), note duration (ms), inter-quartile range bandwidth $(\mathrm{Hz})$, peak frequency $(\mathrm{Hz})$, aggregate entropy, and average entropy (Appendix S1: Table S2, Charif et al. 2010, Köhler et al. 2017). Using the mean value of each parameter for each species, we performed a principal component analysis (PCA) on the log-transformed values using vegan package (Oksanen et al. 2010) in R software (Team 2018). The three first PCA axes captured $92 \%$ of all variation in call parameters (Fig. 2b-c, Appendix S1: Fig. S3, Table S3). The first axis was positively correlated with measures of spectral evenness (aggregate entropy, average entropy, and inter-quartile range bandwidth), ranging from pure-tone-like calls to calls containing wide frequency ranges and harmonics. The second axis was associated with temporal parameters, being positively related to call rate and negatively related to note duration. The third axis was positively correlated with peak frequency and represented characteristics associated with the dominant pitch. Hereafter, we will refer to these three axes as the following acoustic traits: spectral evenness, call timing, and peak frequency.

For each acoustic trait, we tested for phylogenetic signal using Blomberg's K and Mantel test (Appendix S1: Section S1). We also tested the relationship between acoustic traits and body size with a phylogenetic generalized least squares (PGLS) regression using the ape R package (Paradis and Schliep 2018), whereby residual errors are considered to be distributed according to the variance and covariance of phylogenetic distances (Grafen and Hamilton 1989). Here, we used a time-calibrated tree (Jetz and Pyron 2018) pruned to the species observed in our study area.

\section{Distributional patterns of acoustic, body size, and phylogenetic relatedness in signaling assemblages}

This article is protected by copyright. All rights reserved 
To represent the distributional patterns of species' attributes in signaling assemblages, we calculated mean pairwise distances for each of the acoustic traits (spectral evenness, call timing, and peak frequency), body size (snout-vent length; Appendix S1: Section S1), and phylogenetic relatedness, since species sharing more recent ancestry tend to retain more similar ecological requirements. Given potential confounding effects of allometric constraints on acoustic traits, we also assessed the distributional patterns of the model residuals from PGLS on each acoustic trait.

Then, we generated null distributions of mean pairwise distances for each signaling assemblages to be further compared with the observed ones. For each acoustic trait, body size, and phylogenetic relatedness, this procedure involved: (i) computing pairwise distances between species and randomizing them within the family level, (ii) selecting the pairs of most similar species (nearestneighbor distances; Fig. 1b) in each signaling assemblages and averaging the random pairwise distances, (iii) repeating the previous steps 5000 times and obtaining a null distribution per signaling assemblage, and (iv) computing the mean and standard deviation of null mean pairwise distances. We used the nearest-neighbor distances between species in assemblages instead of using all pairs combinations because stronger effects of biotic interactions are more likely to be detected between more similar species (Webb et al. 2002, Tucker et al. 2017).

Next, to summarize the differences between the observed mean pairwise distances and their null distributions, we calculated standard effect sizes (SES) by determining the difference between the observed and the mean of null distribution divided by its standard deviation. Positive SES on mean pairwise distances (SESdist hereafter) indicates that observed distances are greater than those from null models and thus, represent a tendency toward dispersion, while negative values indicate a tendency toward aggregation (Fig. 1c). Our approach is akin to the "Nearest Relative Index" (NRI) often used in trait-based and community phylogenetic approaches (Clarke and Warwick 1998, Webb et al. 2002). We further tested whether SESdist were different from null expectations (i.e., from 0) with a Wilcoxon test (Ingram and Shurin 2009). For these procedures, we used picante (Kembel et al. 2010), vegan (Oksanen et al. 2010), and adephylo (Jombart et al. 2010) R packages.

\section{Distributional patterns of body size and phylogenetic relatedness in local assemblages}

This article is protected by copyright. All rights reserved 
Because our analytical unit considers co-signaling species (signaling assemblages), and the potential influence of environmental filtering is expected to act on the totality of species registered at each site (i.e., local assemblages, $n=39$ ), we also addressed the effect of environmental heterogeneity on the assembly of local assemblages. For such purpose, we calculated SESdist considering the ecological attributes of species (body size and phylogenetic relatedness, a proxy of ecological similarities), calculated for the nearest-neighbor distances of all species at each site. Then, we fitted separate general linear models using aquatic habitat (first two PCA axes), terrestrial habitat (LAI), and vegetation heterogeneity (NDVI) as predictors, and SESdist on body size and phylogenetic relatedness from local assemblages as response variables. Model residuals were inspected to confirm normal distribution and homoscedasticity, and confidence intervals for coefficients were estimated using profile likelihood ratios. SESdist on body size and phylogenetic relatedness for each local assemblage were further used to account for the potential effects of environmental filtering on the observed acoustic structures of signaling assemblages.

\section{Structural equation modeling}

To consider multiple potential drivers of the acoustic space of assemblages, we used structural equation models (SEMs). We first built a single network of variables that worked both as predictors and responses under a hierarchical structure (see predictions Fig. 1d, Appendix S1: Fig. S4), which indicates direct and indirect relationships of multiple variables while reducing the probability of finding spurious correlations under a mechanistic approach (Shipley 2009). To build SEMs, SESdist on acoustic traits, body size, and phylogenetic relatedness of signaling assemblages were averaged per day for the following analysis. Then, we (1) fitted general linear mixed models ( $\mathrm{glmm}$ ) on SESdist of each acoustic trait from signaling assemblages as a function of body size and phylogenetic SESdist, and variables representing environmental heterogeneity (NDVI, terrestrial and aquatic habitats), and (2) fitted a glmm with body size and phylogenetic SESdist as a function of environmental heterogeneity variables. Site was included as random intercept effect in all models. To consider the potential effect of environmental filtering acting on local assemblages, we (3) included paths connecting phylogenetic and body size SESdist from local assemblages (calculated in the previous section) to their corresponding SESdist of signaling assemblages. Because we were unable to link environmental heterogeneity variables and SESdist from local assemblages given the uneven

This article is protected by copyright. All rights reserved 
grouping factors (single values per site), we informed the presence of correlated error structures between them. Goodness of fit was evaluated with a test of directed separation, where significance was assessed with Fisher's $C$ statistic. We report $\mathrm{R}^{2}$ from fixed effect only (marginal) and fixed and random effects together (conditional). Path coefficients were standardized by their standard deviations, allowing them to be compared within the model and to compute indirect effects. SEMs were fit with lme4 (Bates et al. 2015) and piecewiseSEM (Lefcheck 2016) in R.

\section{Results}

From a total of 5,916 2-min audio recordings (197.2 hours), we registered 24 species from four families, with Hylidae (12 species) and Leptodactylidae (9 species) being the most representative ones. The number of species per signaling assemblage (i.e., at the hourly scale) varied from 1 to 12 ( $\bar{x}^{-}$ $=5.5 \pm 2.07 \mathrm{sd}$ ), and per local assemblage (i.e., considering all species registered at each site) from 6 to $19(\bar{x}=10.5 \pm 3.07 \mathrm{sd})$.

We found no evidence of strong niche conservatism on acoustic traits and body size (Appendix S1: Table S4, Fig. S5), with only call timing approaching a Brownian model of trait evolution $(\mathrm{K}=0.99, \mathrm{r}=0.39, \mathrm{p}=0.003)$. As such, the observed acoustic space of these assemblages is not necessarily a by-product of phylogenetic niche conservatism. For frequency-based acoustic traits (spectral evenness and peak frequency), we found a negative relationship with body size while controlling for phylogenetic relatedness $\left(\mathrm{R}^{2}=0.14\right.$ and $0.24, \mathrm{p}=0.03$ and 0.01 , respectively; Appendix S1: Table S5).

SES on mean distances (SESdist) for all acoustic traits, body size, and phylogenetic relatedness tended toward aggregated patterns (Fig. 3, Appendix S1: Table S6), with prevailing negative values different from null expectations (mean values different from 0; Appendix S1: Table S6). SESdist of the residuals from PGLS between acoustic traits and body size also tended toward an aggregated pattern, likewise the original values (Fig. 3). The exception was call timing, with mean original values approaching zero, whereas residual-based SESdist were primarily positive.

When we looked at the phylogenetic and body size SESdist of local assemblages, we found only body size to be related with the second habitat PCA axis $(\beta=-0.57, \mathrm{LCI}=-0.96, \mathrm{UCI}=-0.17$;

This article is protected by copyright. All rights reserved 
Appendix S1: Table S7). Therefore, increasing similarity of body size in local assemblages was associated with breeding sites containing shallower ponds and denser aquatic vegetation.

Using SEM, we found SESdist on spectral evenness to be positively related with vegetation heterogeneity $\left(B=0.31, R^{2} m=0.15, R^{2} c=0.55\right.$; Fig. $\left.4 a\right)$, whereas SESdist on peak frequency showed a positive relationship with phylogenetic SESdist and a negative relationship with and body size SESdist of signaling assemblages ( $\beta=0.4$ and -0.14 , respectively, $R^{2} m=0.16, R^{2} c=0.69$ ). Still within the SEM, SESdist on phylogenetic relatedness of signaling assemblages was positively related to the corresponding SESdist from local assemblages $\left(\beta=0.49, R^{2} m=0.28, R^{2} c=0.58 a\right)$, whereas SESdist on body size $\left(\mathrm{R}^{2} \mathrm{~m}=0.13, \mathrm{R}^{2} \mathrm{c}=0.24\right)$ was positively related to aquatic habitat $(\mathrm{PC} 2, \beta=$ 0.27 ) and vegetation heterogeneity (NDVI, $\beta=0.22$ ). The strongest indirect effect was through the moderation of phylogenetic structure on peak frequency structure ( $B$ ind. $=0.39$, Fig. $4 \mathrm{c}$ ).

\section{Discussion}

Our findings of higher acoustic similarity in signaling anuran assemblages and the correlates of between-assemblage variation contribute to elucidate the drivers of the acoustic space. First, the absence of a dispersed acoustic space invalidates acoustic partitioning. Assemblages were more similar than expected at random both in acoustic and phylogenetic relatedness, but the absence of strong phylogenetic signal in the spectral acoustic traits prevents endorsing niche conservatism alone to be the main driver. We found no remarkable differences in the acoustic space after controlling for the effects of body size, undermining a predominant influence of allometric constraints. Considering between-assemblage variation, we expected niche conservatism and allometric constraints to promote strong associations among acoustic space and phylogenetic and body size similarities, and we also raised that the acoustic space could be indirectly shaped by the sorting species according to their ecological attributes. Results differed according to each spectral acoustic trait, but indirect effects due to a potential effect of environmental heterogeneity were negligible. While aggregation in peak frequency similarity was associated with increasing phylogenetic relatedness, it related negatively with body size similarity. Further, aggregation in spectral evenness was associated with a decrease of vegetation heterogeneity, contrary to expectations based on the acoustic adaptation hypothesis. Altogether, we found little support for the traditional hypotheses of the drivers of the acoustic space

This article is protected by copyright. All rights reserved 
for signaling anurans. Instead, we explain the observed trends of aggregation in the acoustic space in light of species sorting into assemblages upon public information use and phylogenetic niche conservatism. Our findings underscore the importance to address between-assemblage variation in the acoustic space to improve our understanding of the role of ecological and sensory-based processes that has seldom been considered (Chek et al. 2003).

When the ecological context of assemblages was considered, detecting the correlates of between-assemblage variability of acoustic traits provided additional evidence to understand the tendency toward aggregated acoustic space. The positive relationship between phylogenetic and peak frequency similarities could be a side-effect of phylogenetic niche conservatism, wherein community assembly would be mediated by ecological traits correlated with the acoustic ones. Nonetheless, we found no support for environmental filtering acting on the phylogenetic component of signaling assemblages given the lack of association between environmental heterogeneity and phylogenetic relatedness. Conversely, we found similarity in body size of assemblages, which is a trait largely associated with diet and habitat preferences (Womack and Bell 2020), to relate to the structure of aquatic habitat and vegetation heterogeneity. But the indirect effect of environmental filtering on the acoustic space through selection on body size was negligible compared to the direct effect of body size alone, indicating a weak indirect role of environmental filtering. Altogether, we found no evidence that the distribution of the spectral component of assemblages emerges as a by-product of environmental selection.

Species interaction can be mediated by differences in ecological and acoustic traits and consequently, influence the sorting of co-signaling species. Despite the predominant non-dispersed acoustic space, the decreasing aggregation with increasing phylogenetic differences could argue for few particular cases where species would be sorted in communities with lower spectral overlap (Chek et al. 2003). Conversely, an extended communication network between species is expected to promote the assembly of species with similar acoustic and phylogenetic relationships (Tobias et al. 2014). Since species with similar signaling strategies are more likely to exchange information, assemblages relying on social information would have similar signaling patterns (Goodale et al. 2010, Tobias et al. 2014). Theory predicts the net benefit of information use to counteract the potential of negative 
interactions among species (Gil et al. 2019), and thus, public information use in communication networks would potentially influence the ecological overlap among co-signaling species.

Through the lens of social information use, the assembly of species with different body size (lower ecological overlap) and higher similarity in peak frequency (higher acoustic perception) and ecological requirements (phylogenetic relatedness) would have to offset the competitive potential among co-signaling species. Social information can provide reliable hints for predator avoidance (Schmidt et al. 2010, Gil et al. 2018), and under high predation pressure, amphibians are more selective to habitat conditions and increase responsiveness to predation cues (Narayan et al. 2013, Komine et al. 2020). Anurans at low-heterogeneous sites are prone to greater exposure to predators that rely on visual-cues (Ferreira et al. 2019), and the tendency of greater similarity in spectral evenness would favor public information use. Relying on public information can be especially important for anurans in the Pantanal wetlands, where population dynamics are largely influenced by predation risk (Costa-Pereira et al. 2018). However, the literature on the influence of heterospecific information use through acoustics on the assembly of amphibian assemblages is scarce, with most examples coming from birds (Forsman et al. 2009).

Anurans elicit behavioral responses to heterospecific signals (Gerhardt 2001, Both and Grant 2012, Vélez et al. 2017) and use cues gathered inadvertently from heterospecifics to make decisions such as finding suitable breeding sites (Slabbekoorn \& Bouton 2008, Buxton et al. 2015, Buxton and Sperry 2016, Vélez et al. 2017) and engaging in anti-predator behaviors (Phelps et al. 2006). Eavesdropping on species with similar acoustic signals can be especially common in anurans, as signal characteristics should approximate the tuning of the peripheral auditory system (Gerhardt 1994). Acoustic signals not only encode information that is important for conspecifics, but also announce the presence, location, and motivation of emitters (Grafe 2005, Wells and Schwartz 2007), which can increase individual awareness and enhance fitness by reducing costs to access environmental information (Valone 2007). Nevertheless, although eavesdropping on both conspecific and heterospecific signals is widespread over a variety of taxa (Simmons et al. 2003) and characterizes public social information use (Grafe 2005, Magrath et al. 2015), we acknowledge that further experimental studies exploring heterospecific stimuli in anurans will provide more understanding about the potential of communication networks in anuran assemblages.

This article is protected by copyright. All rights reserved 
Variation in similarity of spectral evenness was related to vegetation heterogeneity, with signaling assemblages located in less heterogeneous sites showing greater similarity in spectral evenness. The acoustic adaptation hypothesis predicts that signals are shaped for optimized transmission according to the vegetation structure of a species' habitat (Morton 1975, Ey and Fischer 2009, Erdtmann and Lima 2013), and previous findings suggest that anurans would have higher frequency modulation in heterogeneous habitats (Bosch and De la Riva 2004). In this sense, acoustic adaptation is unlikely to generate the observed variation in the acoustic space, since we found greater similarity at less heterogeneous sites.

The legacy of selective pressures on signal design in determining the acoustic space of signaling communities remains unclear, as addressing past evolutionary processes on present-day patterns requires integrative research on eco-evolutionary dynamics of species interactions, phenotypic evolution, and diversification (Weber et al. 2017). For instance, although acoustic partitioning would promote a divergent pattern in the acoustic space, acoustic traits may have evolved in past and distinct ecological contexts that are unrelated to current competitive interactions. Additionally, our inability to detect the signature of acoustic adaptation can be a limitation of sitebased approaches, which often provide a limited range of environmental conditions required to test the effects of contrasting environments on signal transmission (Carvajal-Castro and Vargas-Salinas 2016). Thus, the role of acoustic competition and adaptation as evolutionary drivers of communitywide patterns should be further explored with emerging techniques combining explicit evolutionary modeling of trait evolution (e.g. Drury et al. 2018) and historical processes involved in community assembly (Pigot and Etienne 2015).

Signaling communities have intrigued ecologists for decades, with several hypotheses being evoked to explain present-day pattern of the acoustic space: selection against signal interference and degradation (acoustic partitioning and acoustic adaptation), species sorting through environmental filtering or extended communication networks (i.e. public information use), and evolutionary constraints (phylogenetic niche conservatism and allometric constraint). We investigated the implications of these potential drivers on the differences in acoustic, ecological, and phylogenetic features of signaling assemblages across gradients of environmental heterogeneity. A tendency toward aggregation in the acoustic space is unlikely to be produced by acoustic partitioning, allometric

This article is protected by copyright. All rights reserved 
constraints, and acoustic adaptation, and we argue that phylogenetic niche conservatism and public information use may underly the overall pattern and the variation observed between assemblages. These findings highlight a multivariate nature of the acoustic dimension that has seldom been considered, and thus, addressing the ecological context of signaling assemblages can improve our understanding of how multiple processes can shape the acoustic space.

\section{Acknowledgments}

We thank Mark Urban and the reviewers for providing constructive criticism on the manuscript, and D.C. Rossa-Feres, M.C. Côrtes, V.S. Saito, and L.F. Toledo for criticism an early version of the manuscript. We thank M.C. Ribeiro for providing audio recorders through grant \#2013/50421-2, São Paulo Research Foundation (FAPESP); Barranco Alto farm owners and crew, R. Costa-Pereira, J.L.M.M. Sugai, G.N. Souza, P. Eveline, S. Duleba, H.S.G. Folly, and L.S. Almeida for assisting in fieldwork, and the Rufford Foundation for Small Grant funding. LSMS and TS acknowledge fundings \#2015/25316-6, \#2017/15772-0, and \#2019/04033-7, São Paulo Research Foundation (FAPESP); Programa Nacional de Cooperação Acadêmica (Procad) 07/2013 project 88881.068425/2014-01 and Programa de Apoio à Pós-Graduação (PROAP) 817737/2015 from Coordenação de Aperfeiçoamento de Pessoal de Nível Superior (CAPES). LSMS acknowledges grant PEJ2018-004603-A from the Spanish Ministerio de Economia, Industria y Competitividad. DLL acknowledges grant \#2016T2/AMB-1722 provided by the Comunidad de Madrid and grant \#CGL2017-88764-R by the Ministerio de Economía, Industria y Competitividad. TSF Silva received grant \#310144/2015-9 from Conselho Nacional de Desenvolvimento Científico e Tecnológico (CNPq) during part of this research. This study was financed in part by the Coordenação de Aperfeiçoamento de Pessoal de Nível Superior-Brasil (CAPES) - Finance Code 001. Authorship statements: Larissa S. M. Sugai conceived the original idea, collected data, and led the writing of the manuscript; Larissa S. M. Sugai, Diego Llusia, and Thiago S. F. Silva contributed to the conception and design of the study. Larissa S. M. Sugai and Diego Llusia analyzed the data; Larissa S. M. Sugai, Diego Llusia, and Tadeu Siqueira interpreted data and discussed results; all authors revised the manuscript critically; Diego Llusia and Thiago S. F. Silva contributed equally to this work.

\section{Supporting Information}

This article is protected by copyright. All rights reserved 
Additional supporting information may be found online at: [link to be added in production]

\section{Open Research}

Data (Sugai et al. 2021) are available in Figshare at: https://doi.org/10.6084/m9.figshare.14229614.v1

\section{Literature cited}

Audacity Team. 2018. Audacity(R): free audio editor and recorder. Version 2.3.1. https://audacityteam.org/.

Bates, D., M. Mächler, B. Bolker, and S. Walker. 2015. Fitting linear mixed-effects models using lme4. Journal of Statistical Software. 67:48.

Berg, K. S., R. T. Brumfield, and V. Apanius. 2006. Phylogenetic and ecological determinants of the neotropical dawn chorus. Proceedings of the Royal Society B: Biological Sciences 273:999-1005.

Bioacoustics Research Program 2014. Raven Pro: interactive sound analysis software (Version 1.5). The Cornell Lab of Ornithology, Ithaca, NY.

Boncoraglio, G., and N. Saino. 2007. Habitat structure and the evolution of bird song: a meta-analysis of the evidence for the acoustic adaptation hypothesis. Functional Ecology 21:134-142.

Bosch, J., and I. De la Riva. 2004. Are frog calls modulated by the environment? An analysis with anuran species from Bolivia. Canadian Journal of Zoology 82:880-888.

Both, C., and T. Grant. 2012. Biological invasions and the acoustic niche: the effect of bullfrog calls on the acoustic signals of white-banded tree frogs. Biology Letters 8:714-716.

Bradbury, J. W., and S. L. Vehrencamp. 2011. Principles of animal communication. Sinauer Associates, Sunderland, MA.

Bréda, N. J. J. 2003. Ground-based measurements of leaf area index: a review of methods, instruments and current controversies. Journal of Experimental Botany 54:2403-2417.

Brumm, H. 2013. Animal communication and noise. Springer, Berlin, Heidelberg.

Buxton, V. L., and J. H. Sperry. 2016. Reproductive decisions in anurans: a review of how predation and competition affects the deposition of eggs and tadpoles. BioScience 67:26-38.

Buxton, V. L., M. P. Ward, and J. H. Sperry. 2015. Use of chorus sounds for location of breeding habitat in 2 species of anuran amphibians. Behavioral Ecology 26:1111-1118.

This article is protected by copyright. All rights reserved 
Carvajal-Castro, J. D., and F. Vargas-Salinas. 2016. Stream noise, habitat filtering, and the phenotypic and phylogenetic structure of Neotropical anuran assemblages. Evolutionary Ecology 30:451-469.

Charif, R., L. Strickman, and A. Waack. 2010. Raven Pro 1.4 user's manual. Ithaca, NY.

Chek, A. A., J. P. Bogart, and S. C. Lougheed. 2003. Mating signal partitioning in multi-species assemblages: a null model test using frogs. Ecology Letters 6:235-247.

Clarke, K. R., and R. M. Warwick. 1998. A taxonomic distinctness index and its statistical properties. Journal of Applied Ecology 35:523-531.

Costa-Pereira, R., V. H. W. Rudolf, F. L. Souza, and M. S. Araújo. 2018. Drivers of individual niche variation in coexisting species. Journal of Animal Ecology 87:1452-1464.

Danchin, É., L.-A. Giraldeau, T. J. Valone, and R. H. Wagner. 2004. Public Information: From Nosy Neighbors to Cultural Evolution. Science 305:487-491.

Drewry, G. E., and A. S. Rand. 1983. Characteristics of an acoustic community: puerto rican frogs of the genus Eleutherodactylus. Copeia 1983:941-953.

Drury, J. P., J. A. Tobias, K. J. Burns, N. A. Mason, A. J. Shultz, and H. Morlon. 2018. Contrasting impacts of competition on ecological and social trait evolution in songbirds. PLOS Biology 16:e2003563.

Endler, J. A. 1992. Signals, signal conditions, and the direction of evolution. The American Naturalist 139:S125-S153.

Erdtmann, L. K., and A. P. Lima. 2013. Environmental effects on anuran call design: what we know and what we need to know. Ethology Ecology \& Evolution 25:1-11.

Evans, T. L., and M. Costa. 2013. Landcover classification of the Lower Nhecolândia subregion of the Brazilian Pantanal Wetlands using ALOS/PALSAR, RADARSAT-2 and ENVISAT/ASAR imagery. Remote Sensing of Environment 128:118-137.

Ey, E., and J. Fischer. 2009. The "acoustic adaptation hypothesis"-a review of the evidence from birds, anurans and mammals. Bioacoustics 19:21-48.

Farjalla, V. F., D. S. Srivastava, N. A. C. Marino, F. D. Azevedo, V. Dib, P. M. Lopes, A. S. Rosado, R. L. Bozelli, and F. A. Esteves. 2012. Ecological determinism increases with organism size. Ecology 93:1752-1759

This article is protected by copyright. All rights reserved 
Ferreira, R.B., Lourenço-de-Moraes, R., Zocca, C., Duca, C., Beard, K.H., and E.D. BrodiE Jr. 2019. Antipredator mechanisms of post-metamorphic anurans: a global database and classification system. Behavioral Ecology Sociobiology 73:69.

Forsman, J. T., M. B. Hjernquist, and L. Gustafsson. 2009. Experimental evidence for the use of density based interspecific social information in forest birds. Ecography 32:539-545.

Garey, M. V., D. B. Provete, T. Gonçalves-Souza, L. S. Ouchi-Melo, C. F. B. Haddad, and D. C. Rossa-Feres. 2018. Phylogenetic and adaptive components of the anuran advertisement call correlate with temporal species co-occurrence. Biological Journal of the Linnean Society 125:292-301.

Gerhardt, H. C. 1994. The evolution of vocalization in frogs and toads. Annual Review of Ecology and Systematics 25:293-324.

Gerhardt, H. C. 2001. Acoustic communication in two groups of closely related treefrogs. Pages 99167. Advances in the Study of Behavior. Academic Press.

Gerhardt, H. C., and F. Huber. 2002. Acoustic communication in insects and anurans: common problems and diverse solutions. Chicago University Press, Chicago, IL.

Gil, M. A., M. L. Baskett, and S. J. Schreiber. 2019. Social information drives ecological outcomes among competing species. Ecology 100:e02835.

Gil, M. A., A. M. Hein, O. Spiegel, M. L. Baskett, and A. Sih. 2018. Social information links individual behavior to population and community dynamics. Trends in Ecology \& Evolution 33:535-548.

Gingras, B., E. Mohandesan, D. Boko, and W. T. Fitch. 2013. Phylogenetic signal in the acoustic parameters of the advertisement calls of four clades of anurans. BMC Evolutionary Biology 13:134.

Goodale, E., G. Beauchamp, R. D. Magrath, J. C. Nieh, and G. D. Ruxton. 2010. Interspecific information transfer influences animal community structure. Trends in Ecology \& Evolution 25:354361.

Goodale, E., H. Sridhar, K. E. Sieving, P. Bangal, G. J. Colorado Z., D. R. Farine, E. W. Heymann, H. H. Jones, I. Krams, A. E. Martínez, F. Montaño-Centellas, J. Muñoz, U. Srinivasan, A. Theo, and K. Shanker. 2020. Mixed company: a framework for understanding the composition and organization of mixed-species animal groups. Biological Reviews 95:889-910.

This article is protected by copyright. All rights reserved 
Grafe, T. U. 2005. Anuran choruses as communication networks. Pages 277-299 in P. K. McGregor, editor. Animal Communication Networks. . Cambridge University Press, Cambridge, UK.

Grafen, A., and W. D. Hamilton. 1989. The phylogenetic regression. Philosophical Transactions of the Royal Society of London. B, Biological Sciences 326:119-157.

Graham, C. H., D. Storch, and A. Machac. 2018. Phylogenetic scale in ecology and evolution. Global Ecology and Biogeography 27:175-187.

Hödl, W. 1977. Call differences and calling site segregation in anuran species from central Amazonian floating meadows. Oecologia 28:351-363.

Ingram, T., and J. B. Shurin. 2009. Trait-based assembly and phylogenetic structure in northeast Pacific rockfish assemblages. Ecology 90:2444-2453.

Jetz, W., and R. A. Pyron. 2018. The interplay of past diversification and evolutionary isolation with present imperilment across the amphibian tree of life. Nature Ecology \& Evolution 2:850-858.

Jombart, T., F. Balloux, and S. Dray. 2010. adephylo: new tools for investigating the phylogenetic signal in biological traits. Bioinformatics 26:1907-1909.

Kembel, S. W., P. D. Cowan, M. R. Helmus, W. K. Cornwell, H. Morlon, D. D. Ackerly, S. P. Blomberg, and C. O. Webb. 2010. picante: R tools for integrating phylogenies and ecology. Bioinformatics 26:1463-1464.

Kime, N. M., W. R. Turner, and M. J. Ryan. 2000. The transmission of advertisement calls in Central American frogs. Behavioral Ecology 11:71-83.

Kingsolver, J. G., and Pfenning, D. W. 2007. Patterns and power of phenotypic selection in nature. BioScience 57: 561-572.

Köhler, J., M. Jansen, A. Rodríguez, P. J. R. Kok, L. F. Toledo, M. Emmrich, F. Glaw, C. F. B. Haddad, M.-O. Rödel, and M. Vences. 2017. The use of bioacoustics in anuran taxonomy: theory, terminology, methods and recommendations for best practice. Zootaxa; Vol 4251, No 1: 11 Apr. 2017 4251:1-11.

Komine, H., K. Fukasawa, M. Akasaka, Y. Watari, N. Iwai, and K. Kaji. 2020. Rapid behavioural responses of native frogs caused by past predation pressure from invasive mongooses. Journal of Zoology 310:126-134.

This article is protected by copyright. All rights reserved 
Kraft, N., W. Cornwell, C. Webb, and D. Ackerly. 2007. Trait evolution, community assembly, and the phylogenetic structure of ecological communities. The American Naturalist 170:271-283.

Lefcheck, J. S. 2016. piecewiseSEM: Piecewise structural equation modelling in $\mathrm{r}$ for ecology, evolution, and systematics. Methods in Ecology and Evolution 7:573-579.

Luther, D. 2009. The influence of the acoustic community on songs of birds in a neotropical rain forest. Behavioral Ecology 20:864-871.

Magrath, R. D., T. M. Haff, P. M. Fallow, and A. N. Radford. 2015. Eavesdropping on heterospecific alarm calls: from mechanisms to consequences. Biological Reviews 90:560-586.

Morton, E. S. 1975. Ecological sources of selection on avian sounds. The American Naturalist 109:17-34.

Nakamura, G., W. Vicentin, Y. R. Súarez, and L. Duarte. 2020. A multifaceted approach to analyzing taxonomic, functional, and phylogenetic $\beta$ diversity. Ecology 00:e03122.

Narayan, E. J., J. F. Cockrem, and J.-M. Hero. 2013. Sight of a predator induces a corticosterone stress response and generates fear in an amphibian. PLOS ONE 8:e73564-e73564.

Oksanen, J., F. G. Blanchet, M. Friendly, R. Kindt, P. Ledengre, D. McGlinn, P. R. Minchin, R. B. O'Hara, G. L. Simpson, P. Solymos, M. H. H. Steven, E. Szoecs, and H. Wagner. 2010. vegan: Community Ecology Package. R in R. p. v. 2.5-3, editor.

Paradis, E., and K. Schliep. 2018. ape 5.0: an environment for modern phylogenetics and evolutionary analyses in R. Bioinformatics 35:526-528.

Pettorelli, N., S. Ryan, T. Mueller, N. Bunnefeld, B. Jedrzejewska, M. Lima, and K. Kausrud. 2011. The Normalized Difference Vegetation Index (NDVI): unforeseen successes in animal ecology. Climate Research 46:15-27.

Phelps, S. M., A. S. Rand, and M. J. Ryan. 2006. The mixed-species chorus as public information: túngara frogs eavesdrop on a heterospecific. Behavioral Ecology 18:108-114.

Pigot, A. L., and R. S. Etienne. 2015. A new dynamic null model for phylogenetic community structure. Ecology Letters 18:153-163.

Roca, I.T., and Proulx, R. 2016. Acoustic assessment of species richness and assembly rules in ensiferan communities from temperate ecosystems. Ecology 97:116-123.

This article is protected by copyright. All rights reserved 
Rodríguez, R. L., M. Araya-Salas, D. A. Gray, M. S. Reichert, L. B. Symes, M. R. Wilkins, R. J. Safran, and G. Höbel. 2014. How acoustic signals scale with individual body size: common trends across diverse taxa. Behavioral Ecology 26:168-177.

Rouse, J. W. J., R. H. Haas, J. A. Schell, and D. W. Deering. 1974. Monitoring the vernal advancements and retrogradation of natural vegetation.

Schmidt, A. K. D., H. Römer, and K. Riede. 2012. Spectral niche segregation and community organization in a tropical cricket assemblage. Behavioral Ecology 24:470-480.

Schmidt, K. A., S. R. X. Dall, and J. A. Van Gils. 2010. The ecology of information: an overview on the ecological significance of making informed decisions. Oikos 119:304-316.

Schwartz, J. J., and M. A. Bee. 2013. Anuran acoustic signal production in noisy environments. Pages 91-132 in H. Brumm, editor. Animal Communication and noise Springer-Verlag, Berlin, Germany.

Seppänen, J.-T., J. T. Forsman, M. Mönkkönen, and R. L. Thomson. 2007. Social information use is a process across time, space, and ecology, reaching heterospecifics. Ecology 88:1622-1633.

Shipley, B. 2009. Confirmatory path analysis in a generalized multilevel context. Ecology 90:363368.

Silva, F. R., J. P. Gibbs, and D. d. C. Rossa-Feres. 2011. Breeding Habitat and Landscape Correlates of Frog Diversity and Abundance in a Tropical Agricultural Landscape. Wetlands 31:1079-1087.

Silva, J. D. S. V., and M. Abdon. 1998. Delimitação do pantanal brasileiro e suas sub regiões. Pesquisa Agropecuária Brasileira 33:1703-1711.

Simmons, A. M., A. N. Popper, and R. R. Fay. 2003. Acoustic communication. Springer-Verlag, New York, NY.

Slabbekoorn, H., and N. Bouton. 2008. Soundscape orientation: a new field in need of sound investigation. Animal Behaviour 76:e5-e8.

Sugai, L. S. M., T. S. F. Silva, J. W. Ribeiro, Jr, and D. Llusia. 2019a. Terrestrial passive acoustic monitoring: review and perspectives. BioScience 69:15-25.

Sugai, L. S. M., J. L. M. M. Sugai, V. L. Ferreira, and T. S. F. Silva. 2019b. Satellite image texture for the assessment of tropical anuran communities. Biotropica 51:581-590.

This article is protected by copyright. All rights reserved 
Sugai, L., D. Llusia, T. Siqueira, and T. S. F. Silva. 2021. Data from: Revisiting the drivers of acoustic similarities in tropical anuran assemblages. Figshare, data set. https://doi.org/10.6084/m9.figshare.14229614.v1

Swenson, N. G., B. J. Enquist, J. Pither, J. Thompson, and J. K. Zimmerman. 2006. The problem and promise of scale dependency in community phylogenetics. Ecology 87:2418-2424.

Team, R. C. 2018. R: A language and environment for statistical computing. R Foundation for Statistical Computing. Vienna, Austria.

Tobias, J. A., R. Planqué, D. L. Cram, and N. Seddon. 2014. Species interactions and the structure of complex communication networks. Proceedings of the National Academy of Sciences 111:10201025.

Toledo L.F., Llusia,D., Vieira C.A., Corbo M. and Marquez R. 2014. Neither convergence nor divergence in the advertisement call of sympatric congeneric Neotropical treefrogs. Bioacoustics 24: $31-47$.

Tonini, J. F. R., D. B. Provete, N. M. Maciel, A. R. Morais, S. Goutte, L. F. Toledo, and R. A. Pyron. 2020. Allometric escape from acoustic constraints is rare for frog calls. Ecology and Evolution 10:3686-3695.

Tucker, C. M., M. W. Cadotte, S. B. Carvalho, T. J. Davies, S. Ferrier, S. A. Fritz, R. Grenyer, M. R. Helmus, L. S. Jin, A. O. Mooers, S. Pavoine, O. Purschke, D. W. Redding, D. F. Rosauer, M. Winter, and F. Mazel. 2017. A guide to phylogenetic metrics for conservation, community ecology and macroecology. Biological Reviews 92:698-715.

Valone, T. J. 2007. From eavesdropping on performance to copying the behavior of others: a review of public information use. Behavioral Ecology and Sociobiology 62:1-14.

Vellend, M. (2016) The theory of ecological communities. Princeton University Press, Princeton, NJ.

Vélez, A., N. M. Gordon, and M. A. Bee. 2017. The signal in noise: acoustic information for soundscape orientation in two North American tree frogs. Behavioral Ecology 28:844-853.

Webb, C. O., D. D. Ackerly, M. A. McPeek, and M. J. Donoghue. 2002. Phylogenies and Community Ecology. Annual Review of Ecology and Systematics 33:475-505.

This article is protected by copyright. All rights reserved 
Weber, M. G., C. E. Wagner, R. J. Best, L. J. Harmon, and B. Matthews. 2017. Evolution in a community context: On integrating ecological interactions and macroevolution. Trends in Ecology \& Evolution 32:291-304.

Wells, K. 2007. The ecology and behavior of amphibians. The University of Chicago Press, Chicago, Illinois.

Wells, K. D., and J. J. Schwartz. 2007. The behavioral ecology of anuran communication. Springer New York, NY.

Womack, M. C., and R. C. Bell. 2020. Two-hundred million years of anuran body size evolution in relation to geography, ecology and life history. Journal of Evolutionary Biology 00:1- 16

This article is protected by copyright. All rights reserved 


\section{Figure captions}

Figure 1. Main hypotheses regarding the potential drivers of the acoustic space of animal signaling assemblages (a). Here, we evaluated the acoustic, phylogenetic, and body size similarities of signaling assemblages using the distributions of nearest neighbor distances between co-signaling species (b). We calculated mean values of nearest-neighbor distances between species (mean pairwise distance) and employed null models to check for trends toward aggregated or dispersed distributional patterns for acoustic traits, body size, and phylogenetic relatedness (c). We tested if the overall patterns in the acoustic space differed from random and build a network of relationships to address betweenassemblage variation of acoustic traits, body size, phylogenetic differences, and environmental heterogeneity $(\mathrm{d} i-\mathrm{v})$. Findings from both analyses were combined to address the potential role of the distinct drivers in influencing the acoustic space across assemblages.

Figure 2. Study area, advertisement calls, and acoustic traits of anuran species in south Pantanal wetlands. (a) Sample sites (yellow dots) in Aquidauana, state of Mato Grosso do Sul, Brazil (Latitude: -19.558234; Longitude: -56.123522, WGS84. Google Earth, earth.google.com/web/). Spectrograms and oscillograms of the advertisement call of some of the recorded anuran species (species codes in Appendix S1: Table S1). Spectral and temporal parameters were quantified and synthesized with a principal component analysis, where (c) the three first axes represented respectively spectral evenness, call timing, and peak frequency.

Figure 3. Standardized effect sizes (SES) of mean pairwise distances of acoustic traits, acoustic traits without the effect of body size (residuals from a PGLS), body size, and phylogenetic distances of anuran assemblage from south Pantanal wetlands of Brazil. Boxplots (white) showing mean, first and third quartiles (notches), and whiskers, surrounded by violin plots (kernel probability distribution).

Figure 4. Structural equation models (SEMs) fitted on the distributional patterns of acoustic traits (spectral evenness, call timing, and peak frequency) of anuran signaling assemblages in south Pantanal wetlands of Brazil. (a) Shown are paths representing relationships with $\mathrm{p}<0.05$ among the specific predictor (gray) and response (yellow) variables (variables in gray letters did not affect response variables), and their standardized beta coefficients to equivalent units, allowing to compare the relative magnitude of different paths. (b) Relationships between acoustic traits and predictors with

This article is protected by copyright. All rights reserved 
paths $<0.05$ in SEMs. (c) Standardized beta coefficients of the direct effects (orange dots) of body size similarities and phylogenetic relatedness on the variability of each acoustic trait and indirect effects (blue dots) mediated by their correspondent distributional patterns in local assemblages, and through environmental heterogeneity variables.

This article is protected by copyright. All rights reserved 
b. SIGNALING ASSEMBLAGES

$\begin{array}{ll}\text { Acoustic interference } & \stackrel{\text { APH Acoustic partitioning }}{\longrightarrow} \text { Dispersed } \\ \text { Habitat structure } & \stackrel{\text { AAH Acoustic adaptation }}{\longrightarrow} \text { Aggregated } \\ \text { Phylogeny } & \stackrel{\mathrm{NCH} \text { Niche conservatism }}{\longrightarrow} \text { Same as phylo } \\ \text { Body size } & \stackrel{\mathrm{ACH} \text { Allometric constraints }}{\longrightarrow} \text { Same as body size } \\ \text { Communication network } & \stackrel{\mathrm{PIH} \text { Publicinformation }}{\longrightarrow} \text { Dispersed }\end{array}$

I c. ACOUSTIC, BODY-SIZE AND PHYLOGENETIC DISTRIBUTIONAL PATTERNS

\section{Mean NN distance}
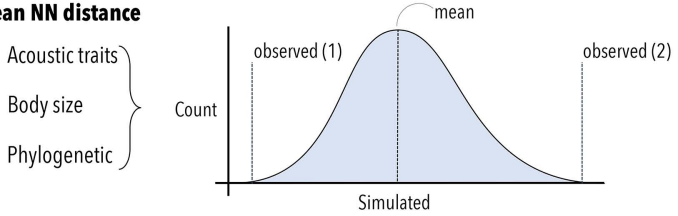

Standardized effect size (observed-simulated)/ std. dev. simulated

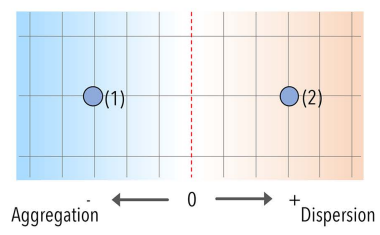

Nearest-neighbor (NN) distances:

- Acoustic

- Body size

- Phylogeny

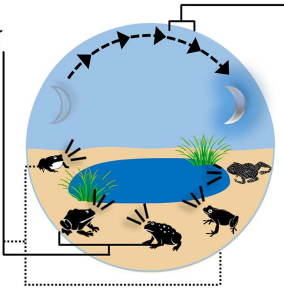

Signaling assemblage (hourly)

I d. Integrating Between-ASSEMblage variation

i. Environmental filtering acting on body size or other ecological traits ii. Ecological similarities relate to the acoustic space (APH and PIH) iii. Acoustic space is a by-product of phylogenetic niche conservatism (NCH) iv. Body size determines the acoustic space (ACH) v. Habitat can influence signal transmission (AAH)

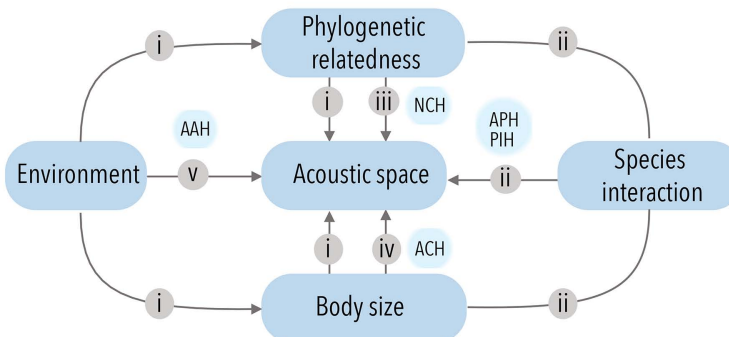


Peak frequency

Call timing

Spectral eveness

Peak frequency (residuals)

Call timing (residuals)

Spectral eveness (residuals)

Body size

Phylogenetic

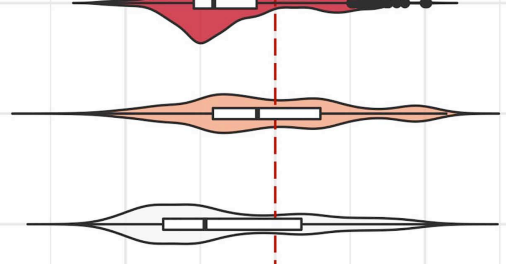




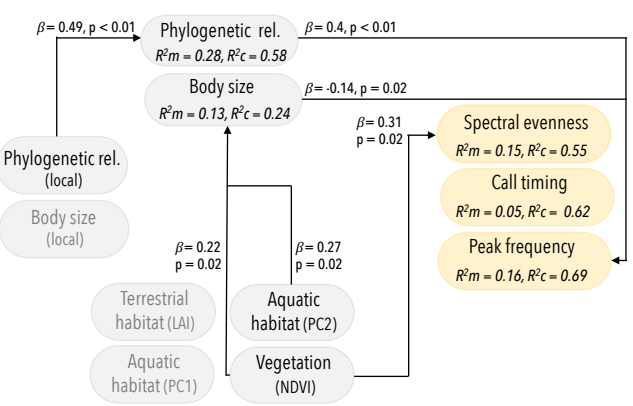

b)

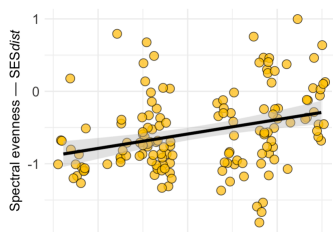

0.3

$$
\begin{aligned}
& 0.4 \\
& \text { NDVI }
\end{aligned}
$$
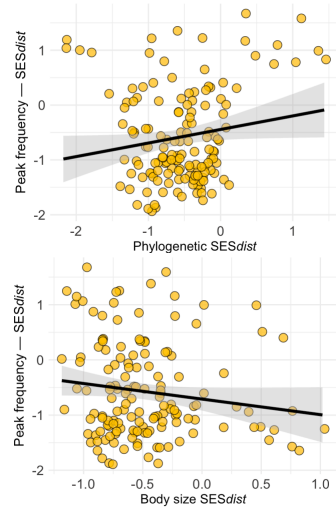

c)

- direct

- indirect

Spectral evenness

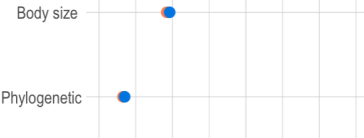

Body size

Call timing

Phylogenetic

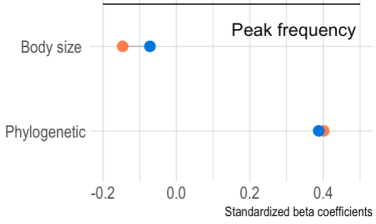

